\section{Ophthalmic management of facial nerve palsy}

V Lee ${ }^{1}$, Z Currie C $^{2}$ and JRO Collin ${ }^{3}$

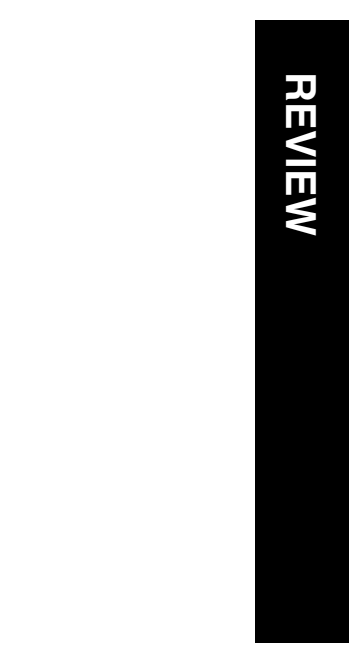

\begin{abstract}
The ophthalmologist plays a pivotal role in the evaluation and rehabilitation of patients with facial nerve palsy. It is crucial to recognize and treat the potentially life-threatening underlying causes. The immediate ophthalmic priority is to ensure adequate corneal protection. The medium to long-term management consists of treatment of epiphora, hyperkinetic disorders secondary to aberrant regeneration and poor cosmesis. Patients should be appropriately referred for general facial re-animation. This review aims to provide a guide to the management of this complex condition.
\end{abstract}

Eye (2004) 18, 1225-1234. doi:10.1038/sj.eye.6701383

Published online 16 April 2004

Keywords: gold weight; tarsorrhapy; facial reanimation; lagophthalmos; aberrant regeneration; epiphora

Normal facial function plays a critical role in a person's physical, psychological, and emotional makeup. Facial disfigurement can affect all these components and can result in social and vocational handicap. The American Medical Association (AMA) Guide to the Evaluation of Permanent Impairment assigns a 'percentage of whole person impairment' percentage of 10-15 and $30-45 \%$, respectively, to describe the impairment imposed by permanent unilateral and bilateral facial paralysis. ${ }^{1}$

The Ophthalmologist plays a pivotal role in the multi-disciplinary team involved in the evaluation and rehabilitation of patients with facial nerve palsy.

\section{Anatomy and aetiology}

The facial nerve arises from the facial nucleus in the pons and passes laterally at the cerebellopontine angle, where it is accompanied by the nervus intermedius (tearing, salivation, taste), and the nerve to the stapedius muscle.
The facial nerve travels with the eighth cranial nerve through the internal auditory canal and through the internal fallopian canal in the petrous temporal bone for the longest interosseus course of any cranial nerve $(30 \mathrm{~mm})$. The fibres for the pterygopalatine ganglion leave at the geniculate ganglion as the greater superficial petrosal nerve. The nerve to the stapedius and the chorda tympani (innervation to the salivary glands) leave prior to the nerve exiting through the stylomastoid foramen as a purely motor nerve to the muscles of facial expression. ${ }^{2}$ Within the substance of the parotid gland, it divides into the five main branches - the temporal, zygomatic, buccal, mandibular, and cervical branches. Facial nerve lesions above the geniculate ganglion classically cause more severe ophthalmic symptoms because lacrimal secretion and orbicularis closure are involved. Central lesions cause crocodile tears when regenerating fibres to the chorda tympani grow down the lacrimal secretory neural pathway. The causes of seventh nerve palsy are myriad, but can be broadly divided into idiopathic, infectious, traumatic, and neoplastic.

\section{Causes}

\section{Idiopathic}

Bell's palsy is defined as an idiopathic paresis or paralysis of the facial nerve. It is typically unilateral, with a sudden onset, and generally spontaneously resolves within 6 months. Many aetiologies have been proposed, including a viral/inflammatory mechanism ${ }^{3,4}$ and systemic steroids and/or acyclovir been recommended as treatment. However, two population-based studies from the $\mathrm{UK}^{5}$ and Canada ${ }^{6}$ have estimated an incidence of 13.1-20.2/100 000 . Both studies found no temporal or geographical clustering to suggest a viral aetiology. The current available evidence from the Cochrane database has shown no significant benefit from
${ }^{1}$ Central Eye Service Central Middlesex Hospital Acton Lane Park Royal Acton London, UK

${ }^{2}$ Department of Ophthalmology Royal Hallamshire Hospital Glossop Road Sheffield, UK

${ }^{3}$ Moorfields Eye Hospital City Road London, UK

Correspondence: Miss V Lee, MA FRCOphth Consultant Ophthalmic Surgeon Central Eye Service Central Middlesex Hospital Acton Lane

Park Royal London NW10 7NS, UK

Tel: 02084532435

Fax: 02084532404

E-mail: vickielee@

mac.com

Received: December 2003 Accepted: 6 November 2003

Published online: 16 April 2004

The authors have no financial or proprietary interest in this study. 
the use of systemic corticosteroids ${ }^{7}$ or acyclovir ${ }^{8}$ in Bell's palsy. A compressive, mechanical aetiology has also been postulated for some cases of Bell's palsy, as another study ${ }^{9}$ found that idiopathic facial nerve palsy occurred three to six times more frequently in pregnant patients.

\section{Infection}

Geniculate ganglionitis (Ramsay Hunt syndrome) caused by herpes zoster is classically associated with zoster vesicles on the ear, in the external auditory canal or tympanic membrane, with vestibulo-auditory symptoms due to the proximity of the eighth cranial nerve in this area. ${ }^{10}$ Lyme disease (Borrelia Burgdorferi) is a known infectious cause of facial palsy, and should be considered in the differential diagnosis of any patient who has visited endemic areas. ${ }^{11}$ Tuberculous otitis media should be considered in the presence of chronic middle ear disease. Facial palsy can be the first presenting sign of AIDS, but is generally described in chronic HIV infection. ${ }^{12}$ Other infections include polio, ${ }^{13}$ mumps, ${ }^{14}$ leprosy, ${ }^{15}$ cat scratch, ${ }^{16}$ and dengue fever. ${ }^{17}$

\section{Traumatic}

Both blunt and penetrating cranio-facial trauma may cause facial nerve injuries. High-resolution-computed tomography is used for localization of nerve injury in suspected cases of temporal bone trauma. In the absence of gross radiographic abnormalities, electrophysiologic testing helps predict the likelihood of spontaneous recovery. In patients with deteriorating facial nerve injuries by electroneuronography, surgical exploration is the preferred management. Primary end-to-end neurorrhaphy is the preferred management for transection injuries, while facial nerve decompression may benefit other forms of high-grade nerve trauma. Secondary facial reanimation procedures (see later) are useful adjuncts when initial facial nerve repair is unsuccessful or impossible. ${ }^{18}$

\section{Neoplastic}

Total ipsilateral facial weakness, decreased tearing (nervus intermedius), hyperacusis (nerve to the stapedius muscle), and associated defects with V, VI, VIII, and Horners syndrome occur classically post surgery to tumours in the cerebellopontine angle. These include acoustic neuromas, meningioma or a globus jugulare tumour. Recovery will occur in cases where the nerve has been bruised or stretched during tumour removal, but is less likely to occur where a large segment of the nerve had to be removed, with or without an interpositional nerve graft. A large review of acoustic neuromas found that the rate of anatomical preservation was $93 \%$, and that there was an increasing preservation of the facial nerve due to special eletrophysiological monitoring. ${ }^{19}$

Malignant tumours of the external auditory canal can cause proximal facial nerve palsy. Malignant parotid tumours and facial nerve schwannomas may all cause facial nerve palsies. Nasopharyngeal carcinoma may affect the spheno-palatine ganglion or cavernous sinus and cause isolated tear deficiency associated with nerve VI palsy.

\section{Other causes}

Facial diplegia is usually due to supranuclear causes (brainstem contusion, glioma, stroke), and rarely results in the same severity of facial paralysis as infranuclear pathology. Other causes include Moebius syndrome and myasthenia gravis.

\section{General evaluation}

The ophthalmologist must determine the likely aetiology, the level of the lesion (proximal/distal), and ensure the treatment of any underlying cause in the acute stages.

\section{Facial nerve grading systems}

The gold standard for grading facial nerve function is the House-Brackmann grading scale. ${ }^{20}$ Due to the limitations and subjectivity of this scale, several new scales ${ }^{21}$ of various degrees of objectivity and ease of use, including systems incorporating computer analysis ${ }^{22,23}$ and moiré photography, ${ }^{24}$ have been introduced.

\section{Ocular complications and treatment}

Paralysis of the orbicularis oculi muscle has implications for lid closure, with risk of corneal exposure.

\section{Corneal exposure and lagophthalmos}

Treatment directed at protecting the cornea depends on the predicted prognosis of return of nerve function and the degree of risk to the cornea based on the amount of lagophthalmos and the quality of Bell's phenomenon and the presence or absence of paralytic ectropion. Estimating the likelihood of recovery requires good communication between all those involved in the patient's care.

\section{Temporary treatment}

Where there is low corneal risk and a good prognosis for recovery, intensive lubricants and taping or padding 
the lid overnight will usually suffice. Where frequent drops are required, preservative-free methylcellulose preparations are helpful and bland ointment can be used at night. The degree of lagophthalmos and the amount of lubricants needed may be reduced with temporary lid loading using external eyelid weights. ${ }^{25}$

Botulinum toxin, injected either transcutaneously through the skin crease or subconjunctivally at the upper border of the tarsus, will produce complete ptosis and afford corneal protection. ${ }^{26}$ The cornea may, however, still be at risk, where there is a poor Bell's phenomenon coupled with marked laxity of the lower lid. This procedure also has the disadvantage of affecting the patient's vision, and may provide less than adequate protection as the levator function returns.

Another means of closure is temporary tarsorrhaphy (central or lateral). This can be achieved with a simple suture $^{27}$ or cyanoacrylate glue $\mathrm{e}^{28}$ as a temporizing measure, and by surgically approximating the posterior lamellae laterally or the grey line centrally, for a more lasting effect. We do not favour the use of the lateral tarsorrhaphy, as it does decrease the monocular temporal visual field and may not adequately close the eye, particularly if there is an accompanying esotropia or significant lower lid ectropion. The classic central tarsorrhaphy is cosmetically and visually poor, but gives good protection. We prefer a 'paracentral' tarsorrhapy carried out lateral to the lacrimal puncta as it offers good closure without affecting the temporal visual field (Figures 1-4). Temporary tarsorrhaphy may be opened at a later date, but there is a risk of subsequent trichiasis that may need further intervention. ${ }^{29}$

\section{Permanent treatment}

Where no functional improvement of the nerve is anticipated, the long-term protection of the cornea is more complex and depends on the degree and manner in which the upper and lower lids are affected. The palpebral aperture can be closed in four ways - by

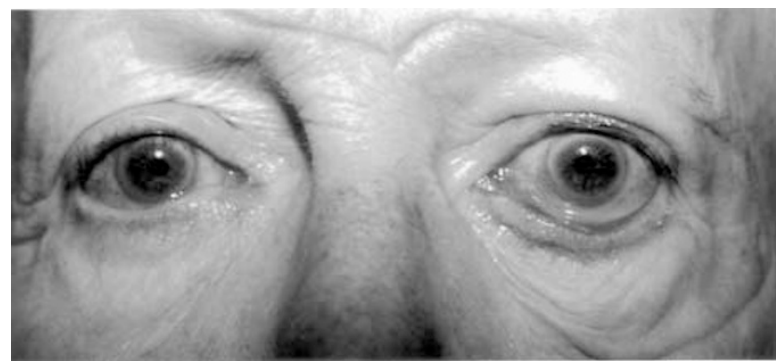

Figure 1 Paralytic ectropion with marked lagophthalmos on attempted eyelid closure.

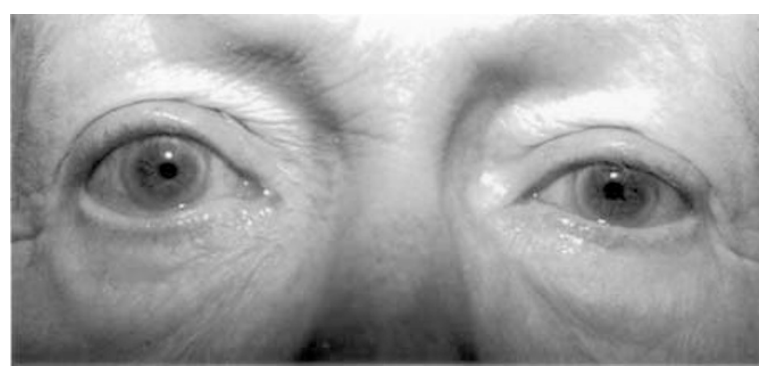

Figure 2 Paracentral (pillar) tarsorrhapy.

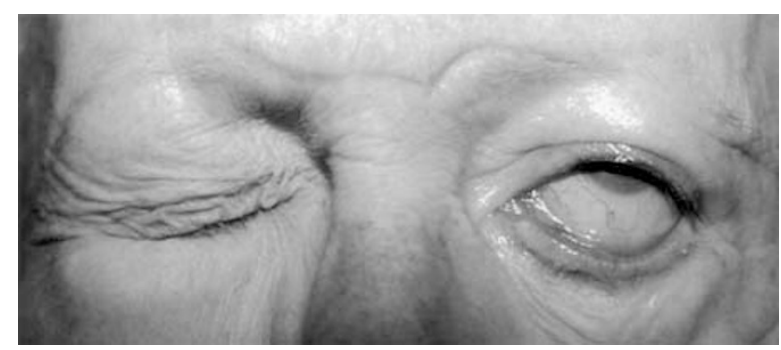

Figure 3 Paralytic ectropion with marked lagophthalmos on attempted eyelid closure.

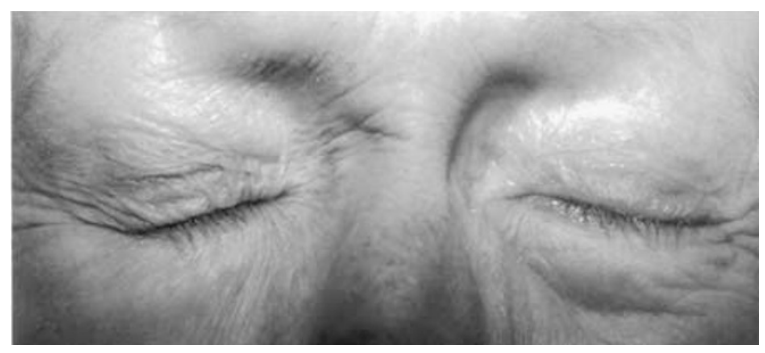

Figure 4 Good eyelid closure post tarsorrhapy.

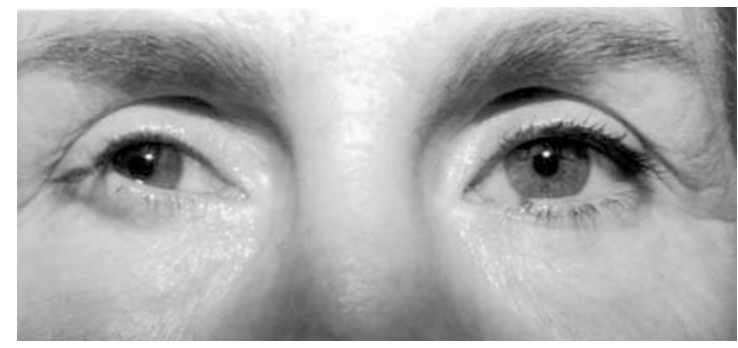

Figure 5 This patient complained of poor cosmesis and restricted visual field from her lateral tarsorrhapy, despite adequate corneal protection.

lowering the upper lid, raising the lower lid, medial and lateral closure (Figures 5 and 6).

Upper lid: In the upper lid, when there is no lid retraction, good closure and an improvement in the quality of the blink can be achieved with gold weight insertion. ${ }^{30,31}$ This is the most commonly performed 


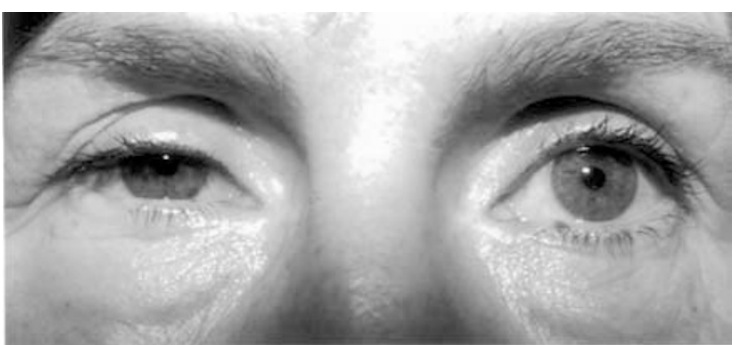

Figure 6 The lateral tarsorrhapy was reversed and the upper lid lowered to decrease the palpebral aperture.

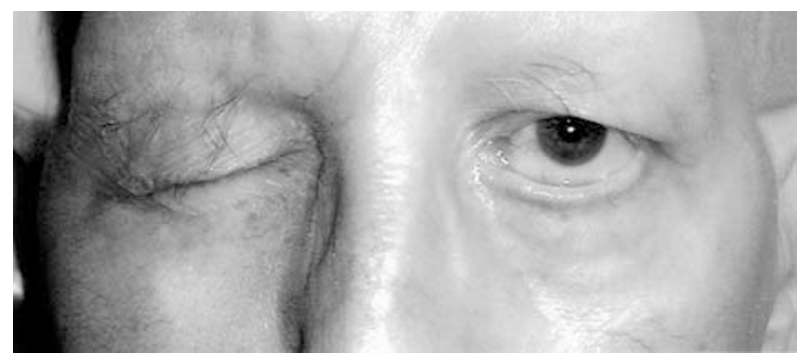

Figure 7 Marked lagophthalmos on attempted eyelid closure.

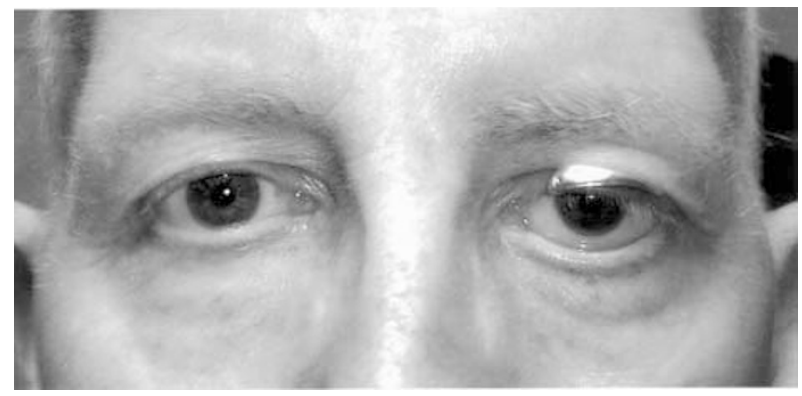

Figure 8 Trial of gold weight.

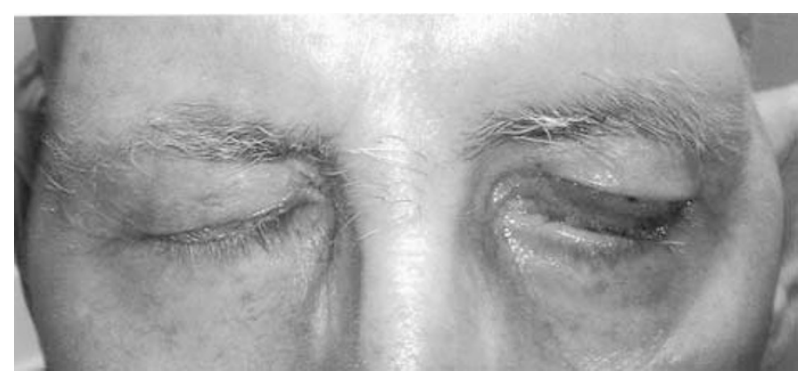

Figure 9 Complete eyelid closure post gold weight insertion - there is partial erosion of the gold weight.

surgery for facial nerve palsy ${ }^{32}$ (Figures 7-9). Complications of infection, allergic reaction, and extrusion can occur, but have been found to be infrequent. ${ }^{33}$ It is equally effective in the early as the later stages, with the advantage that if nerve function improves the weight is easy to remove. ${ }^{34}$ Other methods for producing a mechanical blink include palpebral springs (Figure 10), ${ }^{35}$ periocular silicon slings, ${ }^{36}$ and facial slings.

Lid retraction: Lid retraction is a common sequelae of facial paralysis conventionally thought to be due to the unopposed action of the levator; however, recently, there has been a suggestion that thixotropy (crossbridge formations between actin and myosin filaments causing stiffness of the levator muscle) may play a part. ${ }^{37} \mathrm{Lid}$ retraction must be addressed prior to considering lid loading. There are numerous procedures available for lowering the upper lid and the choice will depend on the amount of retraction. Muller's muscle excision ${ }^{38}$ is sufficient to treat $1-3 \mathrm{~mm}$ of retraction, but with larger amounts retractor recession transconjunctivally ${ }^{39}$ or with an anterior approach (levator recession ${ }^{40}$ or myotomy), with or without a spacer material like sclera, fascia or treated dermis, may be required. ${ }^{41-44}$ The disadvantage with a posterior approach is the postoperative raising of the skin crease. The success of the anterior approach can be augmented with the use of adjustable sutures. ${ }^{45}$

Lower lid: When addressing problems of the lower lid, the choice of surgical procedure will depend on the degree of laxity or ectropion and on the state of the medial and lateral canthal tendons. Also, because of the progressive laxity and stretching of permanently paralysed tissues, a series of different procedures may be required over time.

In practice, merely lengthening the lower lid retractors is not very effective, and increased support to raise the lower lid can be achieved by a combination of medial and lateral canthoplasties (see below). Where there is significant lower lid retraction, this can be combined with insertion of a spacer (tarsus, hard palate, auricular cartilage) ${ }^{46}$ In cases of marked tissue atrophy, an autogenous fascial sling can be threaded hammock-like through the entire length of the lid, anchored by fixation to the medial canthal tendon and the lateral orbital periosteum, to achieve adequate lower lid elevation.

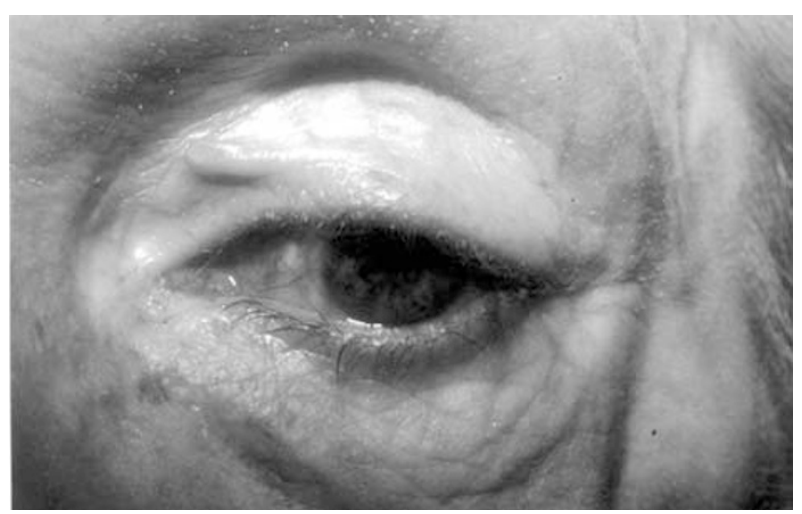

Figure 10 Upper lid palebral spring. 
Lateral: Permanent lateral tarsorrhaphy, because of its poor cosmesis and sometimes ineffectuality, has largely been superseded by the lateral canthal sling. ${ }^{47,48}$ This process of attaching a tarsal strip to the lateral orbital rim has the advantage that it can be augmented by inserting the strip higher on the rim to assist in tear drainage or combining it with a small lateral tarsorrhapy if the horizontal aperture needs to be shortened. ${ }^{49}$ The lateral canthal sling is also frequently combined with a procedure to close the medial canthus (Figures 11 and 12).

Medial: The medial palebral aperture can be closed in several ways - depending on the laxity of the medical canthal tendon. A punctual ectropion can be treated with a medial canthoplasty ${ }^{50}$ or a medial tarsal strip. ${ }^{51}$ Where there is significant tendon laxity, a deep periosteal Royce-Johnston suture (personal communication) (Figures 13 and 14) or a medical wedge excision ${ }^{52}$ could be used.

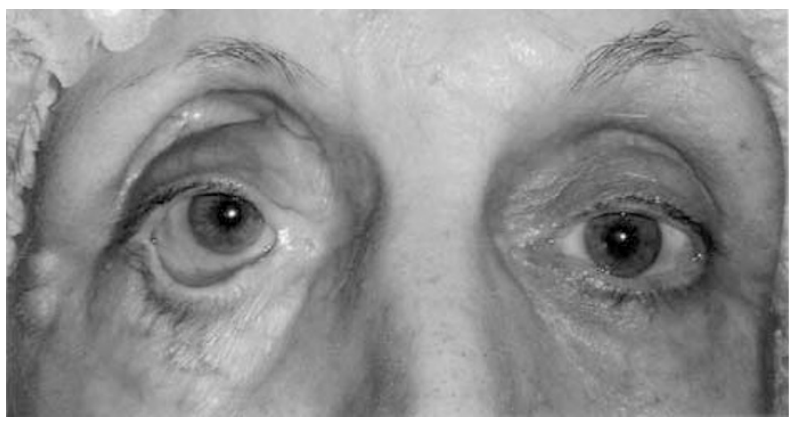

Figure 11

\section{Epiphora}

Reflex tearing from dry eye

This could be improved by reduction of the palpebral aperture and improvement of lid closure.

\section{Paralytic/secondary cicatricial ectropion}

A paralysed orbicularis impairs lacrimal pump function. Doane' $\mathrm{s}^{53}$ slow-motion films have shown that, during a normal blink, the upper lid moves down and nasally, with a corresponding nasal and horizontal excursion in the lower lid, which creates a partial vacuum to facilitate flow through the lacrimal system. This nasal twist is demonstrated to be absent in cases of facial nerve palsy. ${ }^{54}$ An increase in lid laxity exacerbates the functional epiphora. An 'enhanced' lateral tarsal strip can be undertaken to facilitate tear drainage.

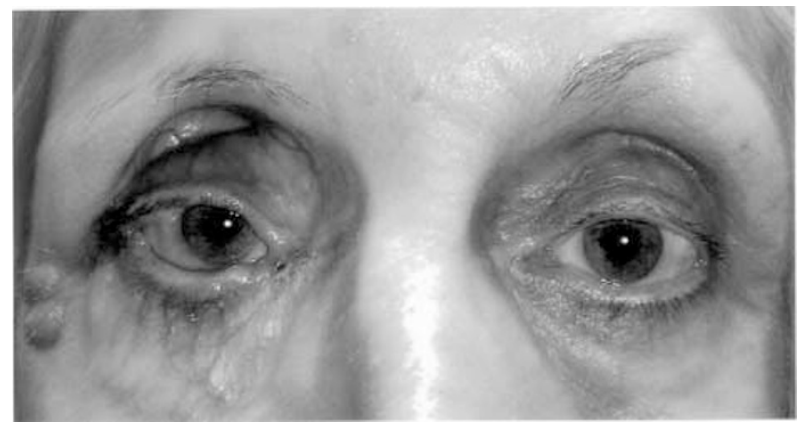

Figure 12

Figure 11 \& 12 Pre- and post-lateral canthal sling and medial canthal Royce-Johnston suture.

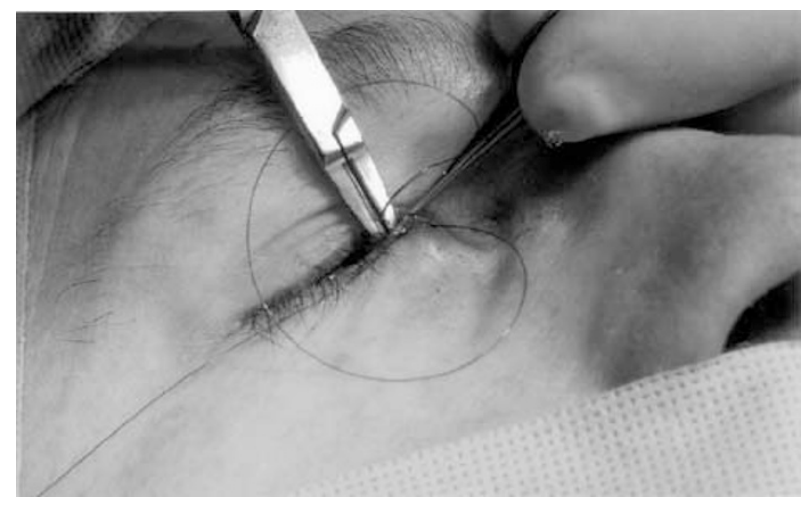

Figure 13

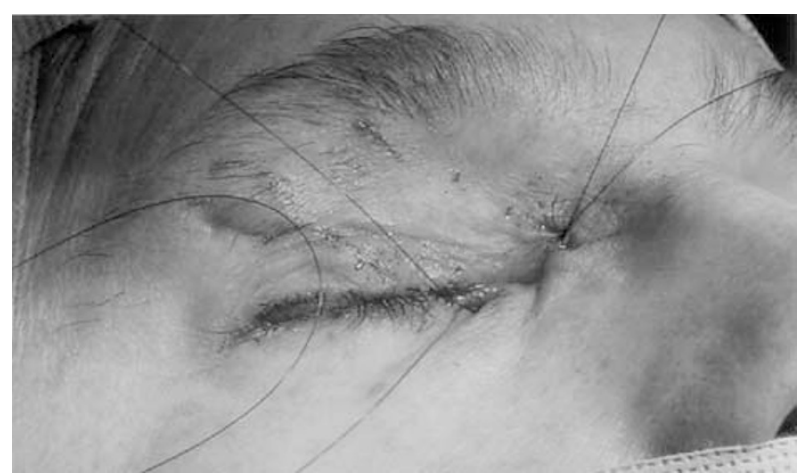

Figure 14

Figure 13 \& 14 The Royce-Johnston (RJ) suture. A double-armed 5/0 prolene passed from the tarsal plate, using a large-diameter free surgical needle supero-medially towards the periosteum of the posterior lacrimal crest. The suture ends were brought out through the skin, tied and buried. 
Dacryocystorhinostomy and Jones tube insertion may be appropriate to decrease the resistance to tear outflow.

\section{Hypersecretion/aberrant innervation of lacrimal gland}

Crocodile tears/gustatory lacrimation results from the misrouting of postganglionic parasympathetic secretomotor fibres. This hypersecretion can be successfully treated with botulinum toxin injections. ${ }^{55}$

\section{Facial hyperfunction}

Synkinetic movements secondary to aberrant regeneration may occur. Typical movements include blinking with oral movement (mimicking jaw winking), ${ }^{56}$ intermittent ptosis (eyelids close when the mouth is closed from misdirection of fibres for the orbicularis oris into the orbicularis oculi) (Figures 15 and 16) and facial spasm with eyelid closure. In our experience, these synkinetic movements respond well to botulinum toxin, with only very low doses required due to the denervation hypersensitivity. Facial hyperfunction secondary to aberrant regeneration must be distinguished from hemifacial spasm, which is classically

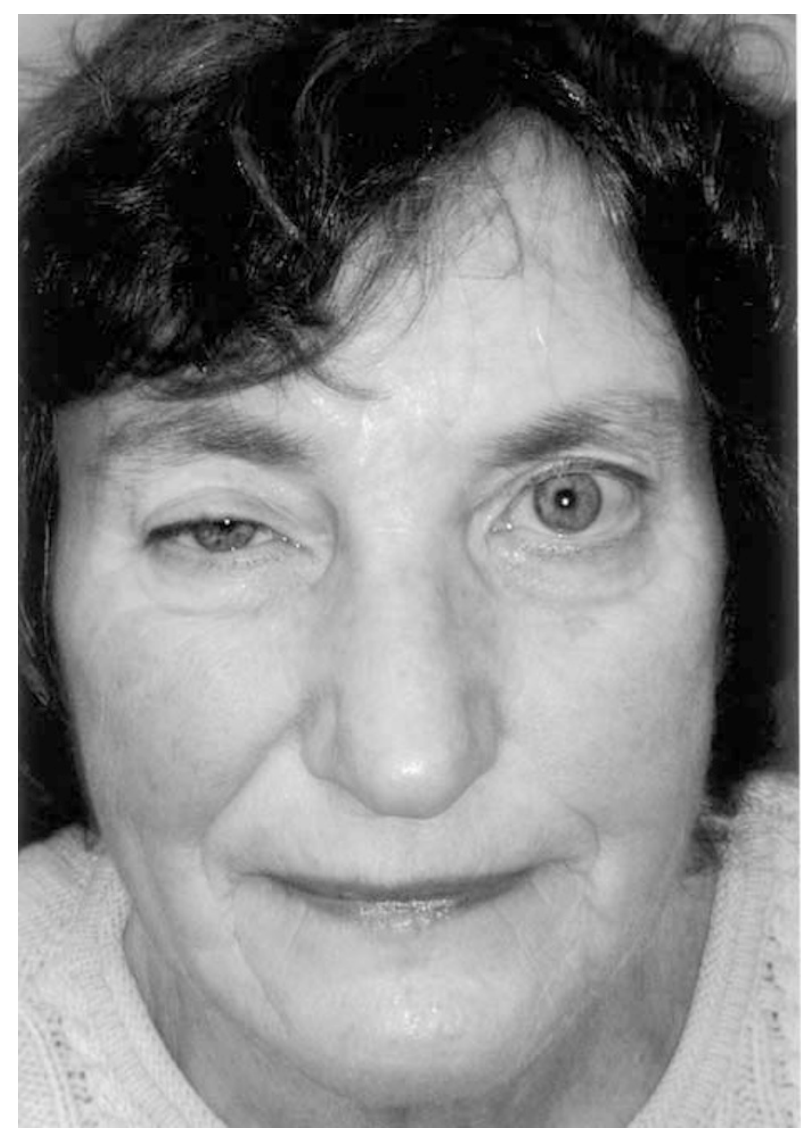

Figure 15 Right aponeurotic ptosis in a patient with previous facial nerve palsy.

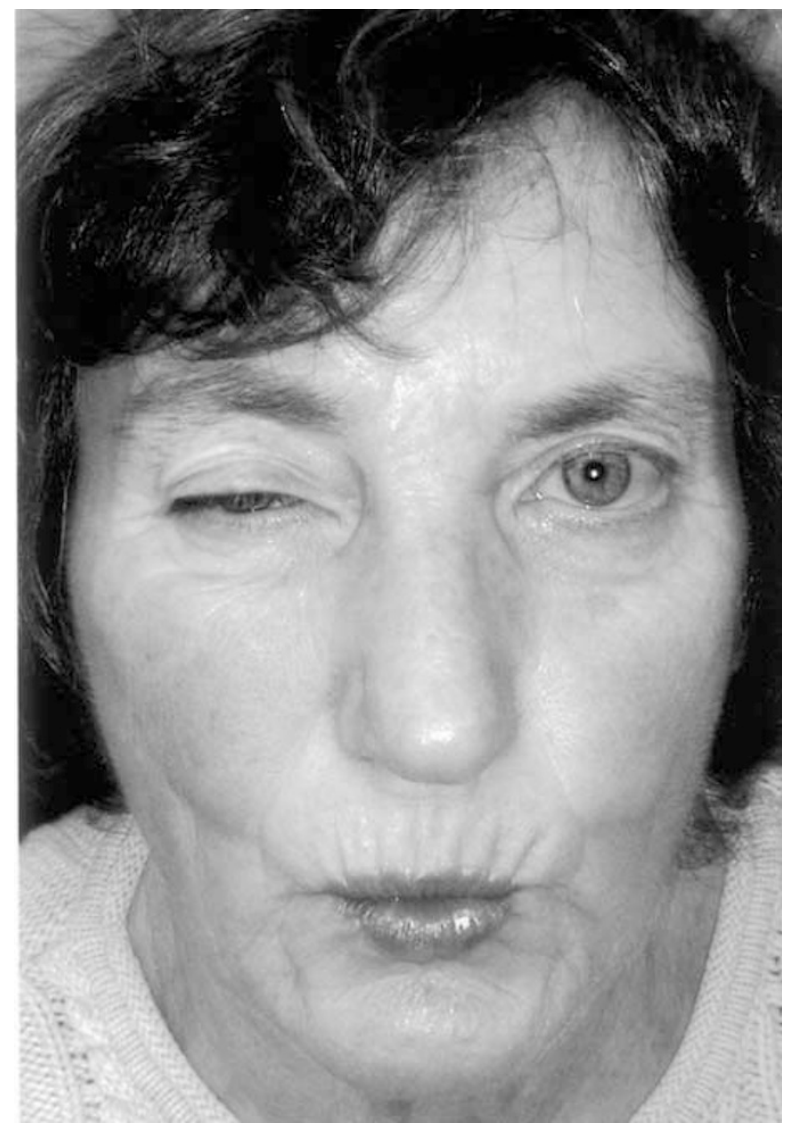

Figure 16 Exacerbation of the ptosis due to aberrant regeneration resulting in co-contraction of orbiculari oris \& oculi.

caused by compression of the facial nerve, by an adjacent artery, which may also result in facial weakness.

\section{Peri-ocular cosmesis}

After correction of the upper and lower lid retraction with appropriate reduction of the palpebral aperture, correction of paralytic ectropion, a patient's cosmesis may further be improved by soft tissue repositioning. This includes correction of brow ptosis either via a direct approach (excision of an ellipse of skin, orbicularis, and frontalis muscle with fixation of deep tissues with nonabsorbable sutures to the periosteum just above the brow), an internal brow lift (where the brow tissues are anchored to the brow periosteum usually via an upper lid blepharoplasty approach) or an endoscopic approach (with a subperiosteal plane of dissection with elevation of the soft tissues on its periosteal pedicle anchored with skull fixation screws). This may be sufficient to correct the upper lid redundancy but, in cases of blepharoptosis (secondary to aberrant innervation or excessive lid skin), blepharoplasty combined with 
levator surgery may be appropriate. These procedures, however, should be confined to patients with no signs of corneal exposure, and we advise conservative skin excision as brow and blepharoptosis contribute to corneal protection. Rehabilitation of the mid-face may be helped by the SOOF (suborbicularis oculi fat pad) lift. ${ }^{57-59}$

\section{Facial physical therapy}

The basic aim of facial rehabilitation is facial symmetry at rest and when facial expressions are being performed. The patient practises appropriate timing and extent of muscle contraction on the affected side to match the expression of the unaffected side of the face. These exercises may be enhanced using surface EMG biofeedback, ${ }^{60}$ and may be particularly useful for disfigurement from facial synkinesis. ${ }^{61}$

\section{Facial reconstruction and reamination}

If there is little likelihood of spontaneous recovery of facial function, the patient should be counselled regarding general facial reanimation. The procedures available may provide static support, increased tone at rest or some degree of voluntary facial movement. However, most of these procedures address lower face deformity with little improvement in voluntary blinking; so ophthalmic rehabilitation should be undertaken regardless of whether a general facial procedure is planned.

\section{Temporalis muscle transfer}

The temporalis muscle tendon is utilized to provide eyelid closure via CN V innervation, with the patient making a chewing/clenching motion. An encircling sling fashioned from the fascia is tunnelled subcutaneously from the lateral to the medial canthus in the upper and lower lids. This procedure can be used in patients with chronic facial nerve palsy, who are not candidates for facial nerve-transfer procedures. This procedure is also extremely effective in improving mouth function. ${ }^{62}$

\section{Microneurovascular free flap transfer}

Microneurovascular muscle transfer is generally indicated if the patient desires dynamic facial reanimation, particularly the restoration of involuntary emotional facial expressions. This procedure is useful in the absence of distal facial nerve fibres or motor endplate function, with a large soft tissue defect in the cheek and where other dynamic reanimations have not been successful. The most commonly used free flaps are gracilis, latissmus dorsi, and inferior rectus abdominus.

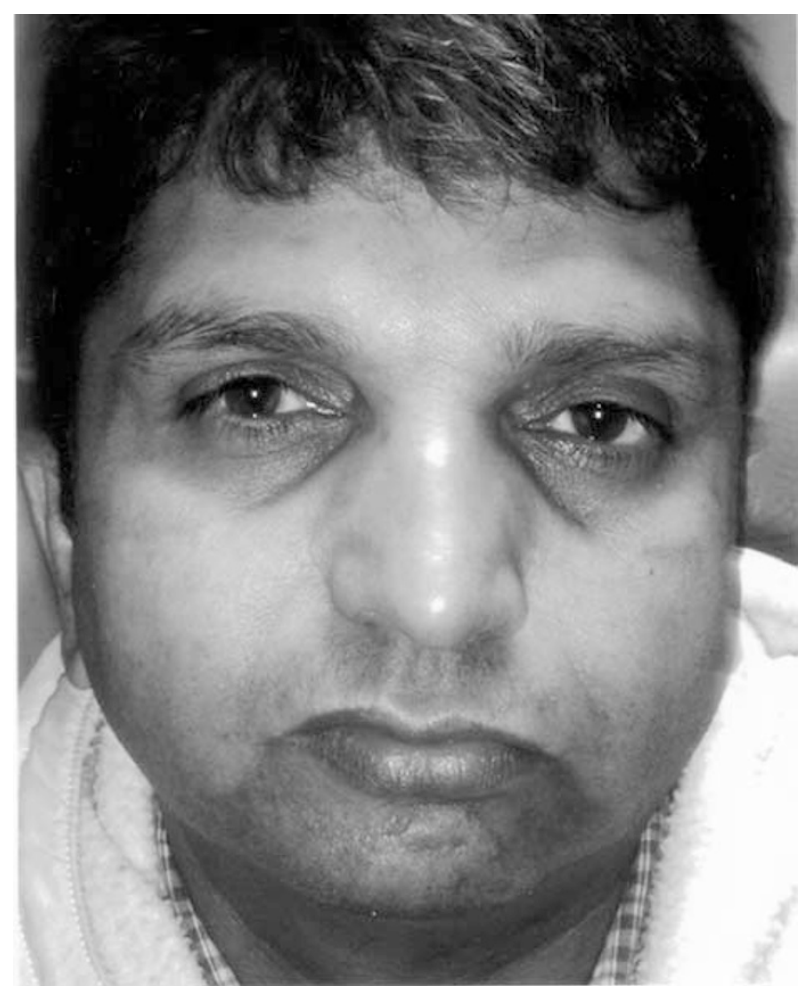

Figure 17 Post hypoglossal-facial anastomosis. There is little sign of facial weakness at rest.

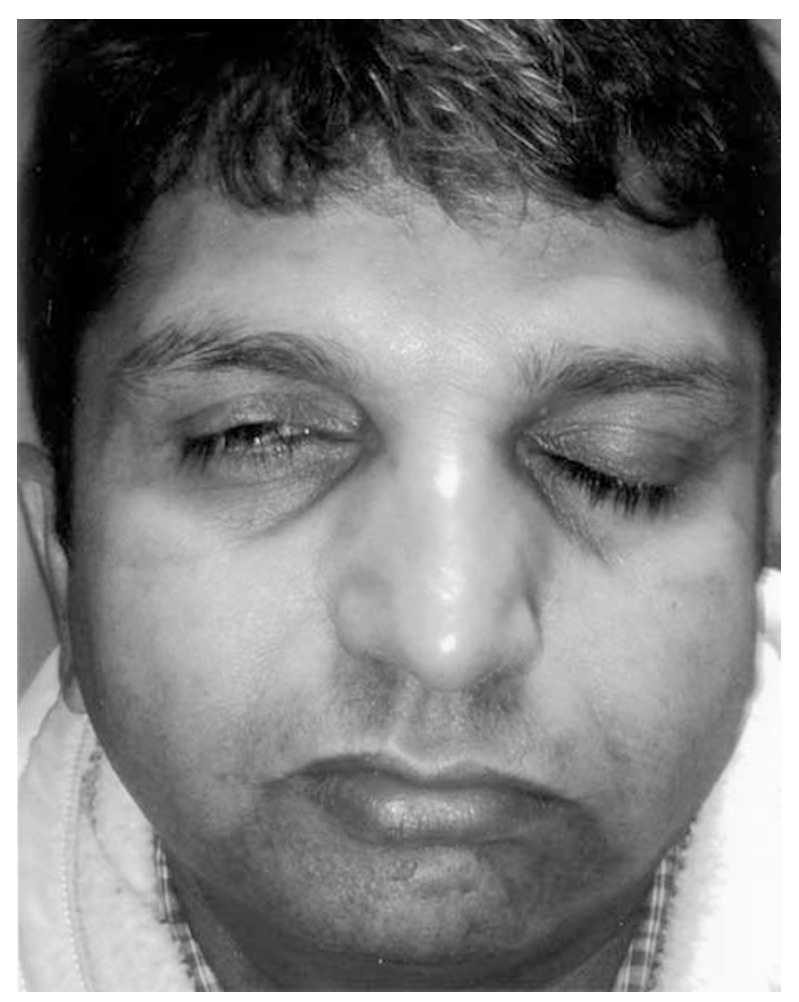

Figure 18 Post hypoglossal-facial anastomosis. Weakness of eyelid closure with lagophthalmos. 


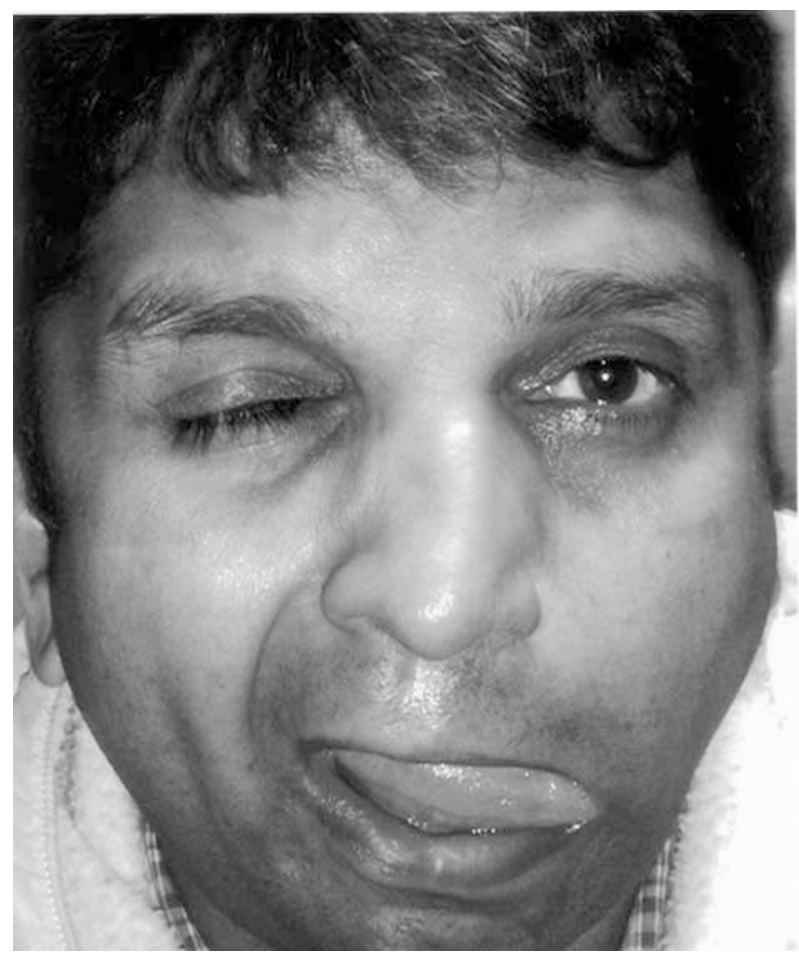

Figure 19 Post hypoglossal-facial anastomosis. Full eyelid closure is achieved when the patient moves his tongue to the contralateral side.
The neurovascular pedicle is anastomosed with the facial nerve, artery, and veins of the normal unaffected side of the face. ${ }^{63}$

\section{Suspension procedures}

A static autogenous fascia lata sling may be used to pull the lip and face upward towards the zygomatic arch. The fascial strips are threaded through the muscles of the mouth with a Wright's fascial needle, and tied tightly on the zygomatic arch. Alternatively, the sling may be passed around the masseter muscle to achieve some degree of dynamic reanimation. ${ }^{64}$ Experience with nonautogenous ${ }^{65}$ materials has been less favourable.

\section{Nerve substitution}

The most effective facial reanimation technique is direct repair of the facial nerve with an end-to-end anastomosis (direct neurorrhaphy). Where this is not possible, the facial hypoglossal anatomosis is one of the most popular methods of reconstructing the facial nerve after proximal injury near to the brain stem (Figures 1719). Conventional methods involve performing a partial hypoglossal nerve section and an interpositional nerve graft to bridge the gap between the two nerves. More

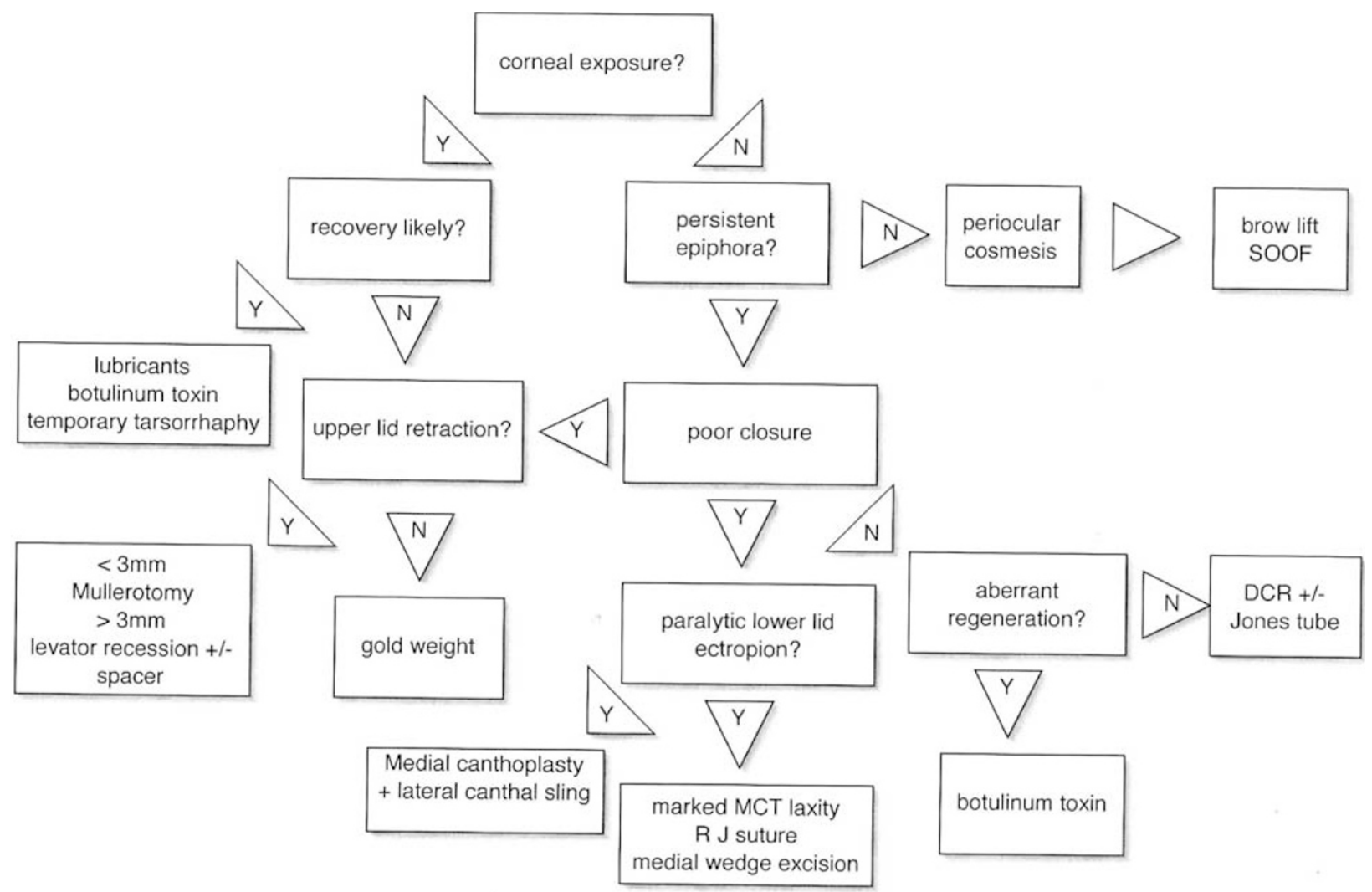

Diagram 1 Schemata for the ophthalmic management of facial palsy. 
recent indirect techniques include end-to-side anastomosis without sectioning the hypoglossal nerve resulting in decreased likelihood of hemiglossal atrophy and its sequelae. Reanimation is generally achieved more successfully in the lower face, and many patients achieve functional adaptation of not needing to think about moving their tongue to animate their face. Lacrimal function is not restored. Other possible anastomosis include the spinal accessory/facial anastomosis, where movement of shoulder causes facial contraction.

\section{Summary}

The ophthalmologist must recognize and treat any underlying causes of facial palsy. The main priority is to ensure adequate corneal protection. The medium to longterm management consists of treating epiphora, hyperkinetic disorders secondary to aberrant regeneration and poor cosmesis (Diagram 1). Where general facial re-animation is desirable, the patient should be referred appropriately.

\section{References}

1 Cocchiarella L, Andersson GBJ Guides to the Evaluation of Permanent Impairment, 5th ed. American Medical Association Press: Chicago, IL, 2001.

2 Sinnatamby CS Last RJ. Anatomy: Regional and Applied, 10th ed. Churchill Livingstone: New York, 1999.

3 Horda H, Taekshashi A. Virus associated demyelination in the pathogenesis of Bell's palsy. Int Med 1992; 31: 1250-1255.

4 Adour KK, Ruboyianes JM, Von Doersten PG, Byl FM, Trent $\mathrm{CS}$, Quesenberry Jr CP, et al. Bell's palsy treatment with acyclovir and prednisone compared with prednisone alone: a double-blind, randomized, controlled trial. Ann Otol Rhinol Laryngol 1996; 105: 371-378.

5 Rowlands S, Hooper R, Hughes R, Burney P. The epidemiology and treatment of Bell's palsy in the UK. Eur J Neurol 2002; 9: 63-67.

6 Morris AM, Deeks SL, Hill MD, Midroni G, Goldstein WC, Mazzulli $\mathrm{T}$ et al. Annualized incidence and spectrum of illness from an outbreak investigation of Bell's palsy. Neuroepidemiology 2002; 21: 255-261.

7 Salinas RA, Alvarez G, Alvarez MI, Ferreira J. Corticosteroids for Bell's palsy (idiopathic facial paralysis). Cochrane Database Syst Rev 2002; 1: CD001942.

8 Sipe J, Dunn L. Aciclovir for Bell's palsy (idiopathic facial paralysis). Cochrane Database Syst Rev 2001; 2: CD001869.

9 Walling A. Bell's Palsy in pregnancy and the puerperium. J Family Pract 1993; 36: 559-563.

10 Sweeney CJ, Gilden DH. Ramsay Hunt syndrome. J Neurol Neurosurg Psychiatry 2001; 71: 149-154.

11 Peltomaa M, Pyykko I, Seppala I, Viljanen M. Lyme borreliosis and facial paralysis - a prospective analysis of risk factors and outcome. Am J Otolaryngol 2002; 23: 125-132.

12 Schot LJ, Devriese PP, Hadderingh RJ, Portegies P, Enting RH. Facial palsy and human immunodeficiency virus infection. Eur Arch Otorhinolaryngol 1994; S498-S500.
13 Moses PD, Pereira SM, John TJ, Steinhoff M. Poliovirus infection and Bell's palsy in children. Ann Trop Paediatr 1985; 5: 195-196.

14 Endo A, Izumi H, Miyashita M, Okubo O, Harada K. Facial palsy associated with mumps parotitis. J Pediatr Infect Dis 2001; 20: 815-816.

15 Lubbers WJ, Schipper A, Hogeweg M, de Soldenhoff R. Paralysis of facial muscles in leprosy patients with lagophthalmos. Int J Lepr Other Mycobact Dis 1994; 62: 220-224.

16 Chiu AG, Hecht DA, Prendiville SA, Mesick C, Mikula S, Deeb ZE. Atypical presentations of cat scratch disease in the head and neck. Otolaryngol Head Neck Surg 2001; 125: 414-416.

17 Patey O, Ollivaud L, Breuil J, Lafaix C. Unusual neurologic manifestations occurring during dengue fever infection. Am J Trop Med Hyg 1993; 48: 793-802.

18 Davis RE, Telischi FF. Traumatic facial nerve injuries: review of diagnosis and treatment. J Craniomaxillofac Trauma 1995; 1: $30-41$.

19 Samil M, Matthies C. Management of 1000 vestibular schwannomas (acoustic neuromas): the facial nerve preservation and restitution of function. Neurosurgery 1997; 40: 684-694.

20 House RJ, Luetje CM, Doyle KJ Treatment and Diagnosis of Acoustic Tumors, 2nd ed. Singular Publishing Group: San Diego, London, 1997, p 25.

21 Kang TS, Vrabec JT, Giddings N, Terris DJ. Facial nerve grading systems (1985-2002): beyond the HouseBrackmann scale. Otol Neurol 2002; 23: 767-771.

22 Sargent EW, Fadhi Oa, Cohen RS. Measurement of facial movement with computer software. Arch Otolargyngol Head Neck Surg 1998; 124: 313-318.

23 Bajaj-Luthra A, Mueller T, Johnson PC. Quantitative analysis of facial motion components: anatomic and non-anatomic motion in normal persons and in patients with complete facial paralysis. Plastic Reconstr Surg 1997; 99: 1894-1902.

24 Yuen K, Inokuchi I, Maeta M, Kawakai SI, Masuda. Evaluation of facial palsy by moiré topography index. Otolargyngol Head Neck Surg 1997; 567-572.

25 Steiff SR, Boerner M, Carter SR. External eyelid weights in facial nerve palsy. Am J Ophthalmol 1995; 120: 652-657.

26 Ellis MF, Daniell M. An evaluation of the safety and efficacy of botulinum toxin type A (BOTOX) when used to produce a protective ptosis. Clin Exp Ophthalmol 2001; 29: 394-399.

27 Gossman MD, Bowe BE, Tanenbaum M. Reversible suture tarsorrhaphy for eyelid malposition and keratopathy. Ophthalmic Surg 1991; 22: 237-239.

28 Donnenfeld ED, Perry HD, Nelson DB. Cyanoacrylate temporary tarsorrhaphy in the management of corneal epithelial defects. Ophthalmic Surg 1991; 22: 591-593.

29 Perusse P. Localised trichiasis after tarsorrhaphy. Am J Ophthalmol 1992; 114: 104-105.

30 Smellie GD. Restoration of the blinking reflex in facial palsy by a simple lid-load operation. Br J Plast Surg 1966; 19: 279-283.

31 Abell KM, Baker RS, Cowen DE, Porter JD. Efficacy of gold weight implants in facial nerve palsy: quantitative alterations in blinking. Vision Res 1998; 38: 3019-3023.

32 Tucker SM, Santos PM. Survey: management of paralytic lagophthalmos and paralytic actropion. Otolaryngol Head Neck Surg 1999; 120: 944-945. 
33 Jobe R. The use of gold weights in the upper eyelid. $\mathrm{Br}$ J Plast Surg 1993; 46: 343-346.

34 Snyder MC, Johnson PJ, Moore GF, Ogren FP. Early versus late gold implantation for rehabilitation of the paralyses eyelid. Laryngoscope 2001; 111: 2109-2113.

35 Levine RE, Shapiro JP. Reanimation of the paralysed eyelid with the enhanced palpebral spring or gold weight: modern replacements for tarsorrhaphy. Facial Plast Surg 2001; 16: 325-336.

36 Arion HG. Dynamic closure of the lids in paralysis of the orbicularis muscle. Int Surg 1972; 57: 48-50.

37 Aramideh M, Koelman JHTM, Devriese PP, Speelman JD, Ongerboer de Visser BW. Thixotropy of levator palpebrae as the cause of lagophthalmos after peripheral facial nerve palsy. J Neurol Neurosci Psych 2002; 72: 665-667.

38 Tyers AG, Collin JRO Colour Atlas of Ophthalmic Plastic surgery, 2nd ed. Churchill Livingstone: New York, 2001, pp 201-203.

39 Tyers AG, Collin JRO Colour Atlas of Ophthalmic Plastic Surgery, 2nd ed. Churchill Livingstone: New York, 2001, pp 205-207.

40 Tyers AG, Collin JRO Colour Atlas of Ophthalmic Plastic surgery, 2nd ed. Churchill Livingstone: New York, 2001, pp 208-210.

41 Olver JM, Fells P. Henderson's relief of eyelid retraction revisited. Eye 1995; 9: 467-471.

42 Ceisler EJ, Bilyk JR, Rubin PAD, Burks WR, Shore JW. Results of mullerotomy and levator aponeurosis transposition for the correction of upper eyelid retraction in Graves disease. Ophthalmology 1995; 102: 483-492.

43 Doxanas MT, Dryden RM. The use of sclera in the treatment of dysthyroid eyelid retraction. Ophthalmology 1981; 88: 887-894.

44 Rubin PAD, Fay AM, Remulla HD, Maus M. Ophthalmic plastic applications of acellular dermal allografts. Ophthalmology 1999; 106: 2091-2097.

45 Tucker SM, Collin JRO. Repair of upper eyelid retraction. A comparison between adjustable and non-adjustable sutures. Br J Ophthalmol 1995; 79: 658-660.

46 Seigel RJ. Palatal grafts for eyelid reconstruction. Plast Reconstruct Surg 1985; 76: 411-414.

47 Anderson RL, Gordy DD. The tarsal strip procedure. Arch Ophthalmol 1979; 97: 2192-2196.

48 Gunter JP, Hackney FL, Hester Jr TR, Codner MA, Paul MD. Evolution of the lateral canthoplasty. Techniques and indications. Plast Reconstruct Surg 1997; 100: 1396-1408.

49 Kinney SE, Brook MS, Seeley MZ, Foster JA. Oculoplastic surgical techniques for protection of the eye in facial nerve paralysis. Am J Otol 2000; 21: 275-283.
50 Lee OS. An operation for correction of everted lacrimal puncta. Am J Ophthalmol 1951; 34: 575-578.

51 Castroviejo-Bolibar M, de Damborenea A, Fernandez-Vega A. Surgical repair of paralytic lagophthalmos by medial tarsal suspension of the lower lid. Br J Ophthalmol 1996; 80: 708-712.

52 Craword CG, Collin JRO, Moriarty PAJ. The correction of paralytic medial ectropion. Br J Ophthalmol 1984; 68: 639-641.

53 Doane MG. Interactions of eyelids and tears in corneal wetting and the dynamics of the normal human eyeblink. Am J Ophthalmol 1980; 89: 507-516.

54 Arrigg P, Miller D. A new lid sign in seventh nerve palsy. Ann Ophthalmol 1985; 17: 43-45.

55 Keegan DJ, Geerling G, Lee JP, Blake G, Collin JR, Plant GT. Botulinum toxin treatment for hyperlacrimation secondary to aberrant regenerated seventh nerve palsy or salivary gland transplantation. $\mathrm{Br} J$ Ophthalmol 2002; 86: 43-46.

56 Frueh BR. Associated facial contractions after seventh nerve palsy mimicking jaw-winking. Ophthalmology 1983; 90: 1105-1109.

57 Alford EL. The SOOF lift as an adjunct in rehabilitation of facial paralysis: help or hype? Facial Plastic Surg 2000; 16: 345-349.

58 Horlock N, Sanders R, Harrison D. The SOOF Lift: its role in correcting midfacial and lower facial asymmetry in patients with partial facial palsy. Plastic Reconstr Surg 2002; 109: 839-849.

59 Olver JM. Raising the suborbicularis oculi fat (SOOF): its role in chronic facial palsy. Br J Ophthalmol 2000; 84: 1401-1406.

60 Brach JS, VanSwearingen JM. Physical therapy for facial paralysis: a tailored treatment approach. Phys Ther 1999; 79: 397-404.

61 Brach JS, VanSwearingen JM, Lenert JJ, Johnson PC. Facial neuromuscular retraining for oral synkinesis. Plast Reconstr Surg 1997; 99: 1922-1933.

62 May M, Drucker C. Temporalis muscle for facial reanimation. A 13 year experience with 224 procedures. Arch Otolaryngol Head Neck Surg 1993; 119: 378-382.

63 Shindo M. Facial reanimation with microvascular free flaps. Facial Plast Surg 2000; 16: 357-359.

64 Maegawa J, Saijo M, Murasawa S. Muscle bow traction method for dynamic facial reanimation. Ann Plast Surg 1999; 43: 354-358.

65 Constantinides M, Galli SK, Miller PJ. Complications of static facial suspensions with expanded polytretrafluoroehtylene (ePTFE). Laryngoscope 2001; 111: 2114-2121. 